\title{
Effect of locus of warning tone on auditory choice reaction time
}

\author{
J. RICHARD SIMON*, ENRIQUE ACOSTA, JR., and STEVEN P. MEWALDT \\ University of Iowa, Iowa City, Iowa 52242
}

\begin{abstract}
Forty Ss pressed a left- or right-hand key depending on the ear in which they heard a $500-\mathrm{Hz}$ stimulus tone. Half of the Ss were instructed to press the key on the same side as the ear stimulated (corresponding condition), while the other half pressed the key on the opposite side (noncorresponding condition). A $200-\mathrm{Hz}$ warning tone preceded the stimulus tone by either 200 or $400 \mathrm{msec}$. The warning tone was presented to the left ear, the right ear, or to both ears in a predetermined random sequence. The locus of the warning tone affected RT on noncorresponding trials but not on corresponding trials. The effect consisted of a significant slowing of information processing on trials where the warning tone was contralateral to the response. Results were explained in terms of an initial tendency to respond toward the source of the warning tone.
\end{abstract}

Previous research has shown that certain auditory and visual displays provide irrelevant directional cues which affect the rate of information processing. For example, responses to the symbolic content of an auditory command are affected by the real or apparent source of that command (Simon \& Small, 1969; Simon, Craft, \& Small, 1971; Simon, Craft, \& Webster, 1973), and in the same way, responses to the meaning of a visual stimulus are affected by the locus of that stimulus (Craft \& Simon, 1970). The irrelevant directional cue need not involve the same sensory modality as the relevant cue in order to produce its effect. For example, reactions to a right light are significantly faster when its onset is accompanied by a tone in the right ear than when accompanied by a tone in the left ear. Similarly, reactions to a left light are faster when accompanied by a tone in the left ear than when accompanied by a tone in the right ear (Simon \& Craft, 1970).

In all of the research described above, the directional cue occurred simultaneously with the relevant stimulus. That is, the directional cue was either an irrelevant dimension of the stimulus itself or it was provided by a simultaneous but irrelevant stimulus to another sensory modality.

The purpose of the present study was to investigate the effect of an irrelevant directional cue presented prior to the onset of the relevant stimulus. The task, as originally conceived, was a corresponding S-R mapping task. The $\mathrm{S}$ was instructed to press a right- or left-hand key on the same side as the ear in which he heard a monaural stimulus tone. The stimulus tone was preceded by a warning tone in one or both ears. We were concerned with determining whether the irrelevant directional cue produced by the monaural warning tone affected reaction time (RT) to the subsequent stimulus tone and whether this effect represented a facilitation or an interference with processing of the stimulus tone.

*R equests for reprints should be sent to J. Richard Simon, Department of Psychology, University of Iowa, Iowa City, Iowa 52242.
Binaural waming tone trials, which are free of directional cues, provided an appropriate baseline condition for making the latter determination.

If, as expected, the locus of the warning tone provided an irrelevant directional cue that produced a tendency to respond toward its source, then reactions should be faster when warning tone and response were on the same side of the body than when they were on opposite sides. Specifically, we predicted that right responses would be faster when the warning tone was on the right than when it was on the left and that left responses would be faster when the warning tone was on the left than when it was on the right. We recognized, however, that, if these results occurred, an alternative explanation was possible, i.e., that the warning tone in one ear, rather than producing a tendency to respond on the same side, might instead be producing a tendency to "tune in" with that same ear for subsequent stimulation. It might then follow that Ss would respond faster when warning and stimulus tones were in the same ear than when they were in opposite ears. In anticipation of having to choose between these two alternative explanations for the same finding, the present experiment was designed to include a noncorresponding S-R mapping task which was comparable to the corresponding task described above. For the noncorresponding task, Ss were instructed to press the left key in response to right ear stimulation and the right key in response to left ear stimulation. If the warning tone produced a tendency to make an ipsilateral response, then results on the noncorresponding task should be the same as on the corresponding task, i.e., faster reactions when warning tone and response were on the same side (despite the fact that warning and stimulus tones were now heard in opposite ears). However, if the warning tone facilitated responding to subsequent stimulation in the same ear, then the findings for the noncorresponding task should be the reverse of those for the corresponding task, i.e., reactions should be faster when warning tone and response were on opposite sides 
(because on those trials the warning and stimulus tones were heard in the same ear).

Assuming the locus of the warning tone affects subsequent information processing as predicted, we were also interested in determining the persistence of the effect. Presumably, the potency of an irrelevant directional cue dissipates over time. Hence, in the present study, the interval between warning and stimulus tones was manipulated with the expectation that, as warning interval increased, there might be a reduction in the effect of warning tone locus on RT to the ensuing stimulus.

\section{METHOD}

\section{Subjects}

The Ss were 40 right-handed females enrolled in an introductory psychology course at the University of lowa.

\section{Apparatus}

The apparatus measured choice RT to a series of monaural stimulus tones which were presented to $S$ through Grason-Stadler TDH 39 earphones. The S's task was to press a left or right telegraph key depending on the ear in which she heard the stimulus tone. Two telegraph keys were mounted $30 \mathrm{~cm}$ apart on a table in front of $S$. She operated the keys with her left and right index fingers. Each trial consisted of a warning tone presented to one or both ears followed by the monaural stimulus tone. Two Hewlett Packard Model $200 \mathrm{AB}$ audio oscillators were used to generate the tones. The $200-\mathrm{Hz}$ warning tone was presented for $150 \mathrm{msec}$ at a sound pressure of $87 \mathrm{~dB}$ (re .0002 microbar) on monaural trials and $84 \mathrm{~dB}$ on binaural trials so as to yield approximately the same loudness on all trials. The $500-\mathrm{Hz}$ stimulus tone had a sound pressure of $83 \mathrm{~dB}$. It terminated with S's response. There was a $2-\mathrm{sec}$ interval between S's response and the warning tone for the next trial. The interval between of fset of the warning tone and onset of the stimulus was $200 \mathrm{msec}$ on one block of trials and $400 \mathrm{msec}$ on another block.

A series of trials was preprogrammed on punched paper tape which was read by a Digitronics Model 2060 perforated tape reader. A timer started when the stimulus tone was presented and stopped when $\mathrm{S}$ pressed one of the keys. BRS-Foringer solid state logic (Digibits 200 series) provided overall control of stimulus presentation and data acquisition. Responses (i.e., the key used) and response times (in milliseconds) were recorded on paper tape by means of a Roytron Model 518 tape punch.

\section{Procedure and Experimental Design}

Half of the Ss were randomly assigned to a corresponding S-R mapping group, while the other half were assigned to a noncorresponding $S-R$ mapping group. The corresponding group was instructed to press the key on the same side as the ear in which they heard the stimulus tone. The noncorresponding group was instructed to press the key on the opposite side of the ear in which they heard the stimulus tone. Each $S$ performed on two blocks of trials. In one block the interval between warning and stimulus tones was $200 \mathrm{msec}$, while in the other block the interval was $400 \mathrm{msec}$. Half of the $S$ s in each $S-R$ mapping group performed the $200-\mathrm{msec}$ black first, while the other half performed the 400-msec block first. Each block consisted of 18 practice trials and 120 test trials. Each trial consisted of a warning tone to the right ear, the left ear, or to both ears followed by a stimulus tone to either the left or right ear. The six possible treatment combinations each appeared 20 times in a predetermined random order, with the restriction that each

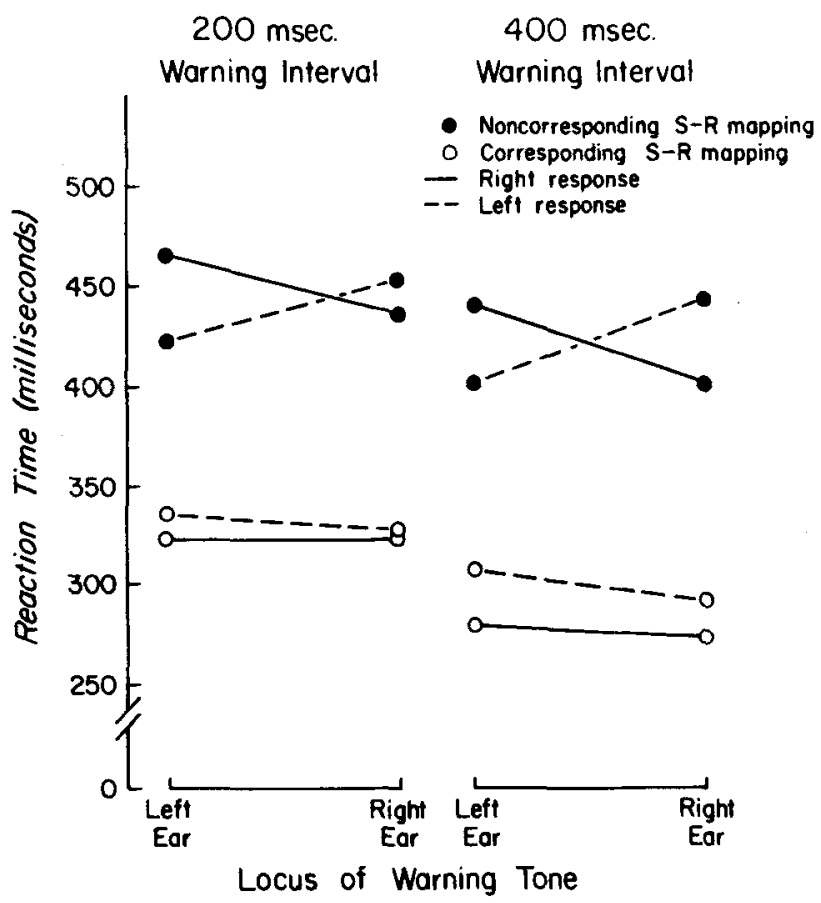

Fig. 1. Effect of locus of a warning tone and warning interval on RT for right and left responses in noncorresponding and corresponding S-R mapping tasks. Note that the speed of information processing on the noncorresponding task is affected by the relative location of the warning tone in relation to that of the response.

occurred five times in each fourth of the trials. The practice trials included three instances of each treatment.

\section{RESULTS}

Median RTs were computed for each $\mathrm{S}$ for each treatment combination represented in each of the two blocks of trials. Data from trials on which errors were made (3\% of the trials) were excluded from the analysis. An overall analysis of variance revealed a significant interaction $(p<.01)$ between blocks (i.e., warning interval) and the sequence in which the blocks were taken. This interaction, which reflected a differential practice effect, meant that no meaningful analysis of the effects of warning interval could be made until the data from the trial block administered second were discarded. The remaining data, then, consisted of two between- $S$ factors, $S-R$ correspondence and warning interval, and two within-S factors, locus of warning tone and response.

Fig. 1 shows the means of the median RTs for those treatment conditions involving a monaural warning tone. An analysis of variance revealed that reactions of the noncorresponding S-R mapping group were significantly slower (433 vs $308 \mathrm{msec})$ than those of the corresponding group $[F(1,36)=85.30, p<.01]$. Since there was also a significant S-R Mapping by Locus of Warning Tone by Response interaction 
$[F(1,36)=11.64, p<.01]$, separate analyses were conducted for each S-R mapping group. For the noncorresponding group, the Locus of Warning Tone by Response interaction was significant $[F(1,18)=12.55$, $p<.01]$. Note, in the top half of Fig. 1, that RT was faster for the left response (i.e., stimulus tone in right ear) when the warning tone was presented in the left ear than when it was presented in the right ear. Similarly, RT was faster for the right response (i.e., stimulus tone in the left ear) when the warning tone was presented to the right ear than when it was presented to the left ear. The identical interaction occurred at both the 200- and $400-\mathrm{msec}$ warning intervals. Responses with the 400-msec warning interval tended to be faster than with the $200-\mathrm{msec}$ interval (421 vs $445 \mathrm{msec}$ ), but the difference was not significant $[F(1,18)=1.03]$. For the corresponding group (lower half of Fig. 1), the Locus of Warning Tone by Response interaction was not significant $[F(1,18)=0.66]$. Responses with the 400-msec warning interval were significantly faster than with the $200-\mathrm{msec}$ interval (289 vs $328 \mathrm{msec})$ $[\mathrm{F}(1,18)=7.71, \mathrm{p}<.01]$.

An additional analysis was performed to determine whether the irrelevant directional cue in the monaural warning tone had a facilitative or inhibitory effect on information processing. For this analysis, the binaural warning tone trials provided an appropriate baseline since there is no directional cue associated with a warning tone presented to both ears. The procedure followed was to collapse the six treatments within a block into three categories of warning tone/response relationship: (1) trials involving warning tone and response on opposite sides (i.e., left warning tone/right response and right warning tone/left response), (2) trials involving warning tone and response on the same side (i.e., right warning tone/right response and left warning tone/left response), and (3) trials involving a binaural warning tone (i.e., binaural warning/right response and binaural warning/left response). Table 1 summarizes the mean RT for the three treatments combined across warning intervals for each S-R mapping group. This analysis again revealed that the noncorresponding group was significantly slower than the corresponding group (427 vs $305 \mathrm{msec}) \quad[\mathrm{F}(1,36)=92.94, \mathrm{p}<.01]$. An analysis of the noncorresponding group alone revealed a significant effect of warning tone/response relationship $[F(2,36)=7.83, p<.01]$. Follow-up $1 \mathrm{df}$ contrasts indicated that a warning tone contralateral to the response produced significantly slower reactions (446 msec) than an ipsilateral tone $(416 \mathrm{msec})$ or a binaural tone $(420 \mathrm{msec})$. There was no difference between the latter two means. In other words, results indicate that a warning tone contralateral to the response interfered with information processing, but a warning tone ipsilateral to the response did not facilitate information processing. A similar analysis of the corresponding S-R mapping group indicated that the overall effect of warning tone/response relationship was not significant $[F(2,36)=1.69]$, so no individual contrasts were made.

\section{DISCUSSION}

Results of the present study indicate that an irrelevant directional cue contained in a warning signal can, under certain conditions, interfere with the processing of subsequent information. This interference effect occurred in a choice RT task involving noncorresponding S-R mapping but not in a comparable task involving corresponding S-R mapping. This finding was replicated on different groups of Ss using different warning intervals. The literature contains other examples of phenomena or relationships which seem to be dependent upon the compatibility of the task. For example, Leonard (1959) found that the usual relationship between RT and the number of response alternatives did not hold in a highly compatible task. Similarly, Broadbent and Gregory (1962) found that the classic difference between Donders's $b$ and $c$ reactions occurred only with rather incompatible S-R relationships.

What is the explanation for the present findings, i.e., that the irrelevant cue had the predicted effect on the more complex task but not on the simple task? To reiterate, we had hypothesized that the irrelevant directional cue in a monaural warning tone would produce a tendency to react toward the source of the tone. For example, on a trial in which a warning tone in the right ear was followed by a stimulus signaling a left response, we expected that the warning tone would tend to elicit a right response which $S$ would first have to override before responding to the stimulus tone, thus producing a delay in information processing. Specifically, we had predicted that reactions would be faster when warning tone and response were on the same side of the body than when they were on opposite sides. Why did this expected result occur in the noncorresponding task but not in the corresponding task?

The explanation, we believe, lies in the relative strength of competing response tendencies. In the corresponding S-R mapping task, S, was instructed to press the key on the same side as the ear stimulated.

Table 1

Reaction Time (in Milliseconds) in Noncorresponding and Corresponding S-R Mapping Tasks as a Function of the Relative Location of the Warning Tone in Relation to the Response

\begin{tabular}{llc} 
& \multicolumn{2}{c}{ S-R Mapping } \\
\cline { 2 - 3 } Warning Tone/Response Relationship & NC & C \\
\hline Warning tone and response on opposite sides & 446 & 306 \\
Warning tone and response on the same side & 416 & 310 \\
Binaural warning tone & 420 & 299 \\
Mean & 427 & 305 \\
\hline
\end{tabular}

Note $-N C=$ noncorresponding, $C=$ corresponding. 
These instructions corresponded with a strong natural tendency to respond to a stimulus in one ear by making an ipsilateral response. There was little or no tendency to make the competing contralateral response. In this situation, then, any additional response tendency elicited by the warning tone was not potent enough to affect the balance between already unequal response tendencies associated with the stimulus. In the noncorresponding task, however, the situation was different. The $\mathrm{S}$ was instructed to press the key on the opposite side of the ear stimulated. These instructions conflicted with the strong natural tendency to make an ipsilateral response. The slower RT on the noncorresponding task reflects the competition between the tendency to make the response as instructed and the tendency to make the response that was natural. The point, however, is that in this situation involving relatively equal but competing responses to the stimulus, the added response tendency elicited by the warning tone was potent enough to produce a significant effect.

In summary, the present research extends our understanding of a stereotypic tendency to react toward the stimulus source by specifying the range of situations in which the stereotype operates. Results revealed that an irrelevant directional cue presented prior to the onset of a relevant stimulus can interfere with the processing of that stimulus. Whether or not interference occurred, however, depended on the nature of the response which was required to the relevant stimulus. No interference occurred in the corresponding S-R mapping task where the required stimulus-response association was strong. It was only in the noncorresponding task, where the required response was not strongly associated with the stimulus, that the locus of the warning tone had any effect. Results suggest, then, that the irrelevant directional cue affects the response selection stage of information processing, since the difference between our corresponding and noncorresponding tasks was purely a difference in response assignment. Finally, our manipulation of the warning interval indicated that the interference was as potent at $400 \mathrm{msec}$ following the warning tone as it was at $200 \mathrm{msec}$. Unfortunately, the limited range of intervals included in the present study does not permit a specification of the maximum duration of the interference effect.

\section{REFERENCES}

Broadbent, D. E., \& Gregory, M. Donders' B- and C-reactions and S-R compatibility. Journal of Experimental Psychology, $1962,63,575-578$.

Craft, J. L., \& Simon, J. R. Processing symbolic information from a visual display: Interference from an irrelevant directional cue. Journal of Experimental Psychology, 1970, 83, 415-420.

Leonard, J. A. Tactual choice reactions: I. Quarterly Journal of Experimental Psychology, 1959, 11, 76-83.

Simon, J. R., \& Craft, J. L. Effects of an irrelevant auditory stimulus on visual choice reaction time. Journal of Experimental Psychology, 1970, 86, 272-274.

Simon, J. R., Craft, J. L., \& Small, A. M., Jr. Reactions toward the apparent source of an auditory stimulus, Journal of Experimental Psychology, 1971, 89, 203-206.

Simon, J. R., Craft, J. L., \& Webster, J. B. Reactions toward the stimulus source: Analysis of correct responses and errors over a five-day period. Journal of Experimental Psychology, 1973, 101, 175-178.

Simon, J. R., \& Small, A. M., Jr. Processing auditory information: Interference from an irrelevant cue. Journal of Applied Psychology, 1969, 53, 433-435.

(Received for publication June 17, 1974; accepted July 20,1974 .) 